\title{
Por que progressão continuada?
}

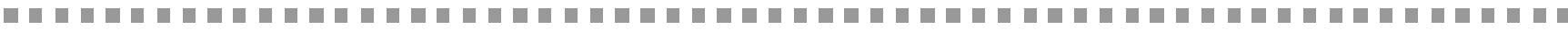

Moacir Gadotti

PAlMA FILHO, J. C.; AlveS, M. L.; DURAN, M. C. G. Ciclo Básico em São Paulo: memórias da educação nos anos 1980. São Paulo: Xamã, 2003.
\end{abstract}

Existem muitas críticas, fundamentadas, ao sistema educacional brasileiro. $\mathrm{O}$ desafio de uma educação de qualidade para todos não foi ainda enfrentado de forma definitiva. Há, contudo, inegáveis exemplos de avanços que precisam ser reconhecidos e melhor analisados para que não ocorram retrocessos. Esse é o caso do chamado "regime de ciclos", tão criticado hoje, cujas origens e implantação são objeto de investigação e cuidadosa revisão crítica, no livro, publicado pela Xamã, Ciclo Básico em São Paulo: memórias da educação nos anos 1980.

João Cardoso Palma Filho, Maria Leila Alves e Marília Claret Geraes Duran não só viveram o processo de criação do Ciclo Básico no Estado de São Paulo, durante a gestão de Franco Montoro (1983-1987), como fizeram parte de sua concepção e implantação. Não houve consenso na época, e as resistências, principalmente do magistério, foram muito grandes. O Ciclo Básico poderia ter sido implantado, naquele período, com maior discussão na rede, através de um processo mais democrático, como reconhecem os autores desse estudo. Contudo, não podemos negar o mérito de se ter enfrentado, pela primeira vez no Brasil, o fantasma da repetência e da evasão escolar, principalmente da primeira para a segunda série do ensino fundamental. Na época, eu estava na coordenação do Fórum de Educação do Estado de São Paulo e o tema foi objeto de discussão em diferentes momentos de suas "sessões públicas". Estava claro, para todos nós, que o "Ciclo Básico” seria implantado com o objetivo de enfrentar o elitismo e a seletividade da escola pública de São Paulo, estampados nas altas taxas de reprovação e evasão.

Por que, então, o regime de ciclos e a progressão continuada são hoje tão criticados?

A palavra "ciclo" não é realmente adequada para expressar mudança. Ao contrário, ela expressa "repetição de fatos". Mas não é pela etimologia que o regime de ciclos e a progressão continuada são criticados. Se, de um lado, a defesa do regime de ciclos justifica-se pedagógica e politicamente, de outro obriga-nos a explicar o seu fracasso em alguns sistemas de ensino. Retomar sua origem, como o fazem os autores desse estudo, ajuda-nos a entender melhor o que está acontecendo hoje. Em geral, os educadores têm aceitado a tese da progressão continuada por ciclos e atribuem o seu fracasso à forma autoritária e pragmática com que vem sendo implantada, visando apenas à mudança nas estatísticas de desempenho da 
rede pública de ensino. A solução não estaria na retomada da reprovação e da seriação, mas na eliminação das causas do fracasso do regime de ciclos. E quais são essas causas?

Em primeiro lugar, o que "mata" a proposta dos ciclos é a arrogância da sua decretação, o autoritarismo com que ela é, às vezes, implantada. Trata-se, por isso, de inserir a discussão na escola, formando professores, pais, alunos e toda a comunidade escolar para essa reforma estrutural e cultural. A progressão continuada mexe profundamente com a cultura escolar elitista e sua implantação não será bem-sucedida sem uma mudança nessa cultura.

Ninguém se sente responsável pela implantação de um projeto de reforma do ensino se não for previamente envolvido com sua concepção e criação. O Estado precisa criar as condições para que o(a) professor(a) sinta-se responsável pelas reformas educacionais, incluindo planos de carreira sérios, o que hoje é muito difícil, pois eles trabalham em várias escolas devido aos baixos salários e à contratação por disciplina, e não por tempo de trabalho.

Em segundo lugar, eu diria que são necessárias medidas correlatas, suficientemente importantes, para não pôr em risco o projeto, caso não forem também levadas em sua devida conta. Trata-se de ampliar a autonomia da escola para que esta insira em seu projeto político-pedagógico o regime de ciclos. A progressão continuada deve fazer parte de sua opção, e não apenas da opção política dos dirigentes das Secretarias de Educação. A implantação dos ciclos não pode ser separada da construção do projeto político-pedagógico das escolas, para que cada uma delas, individualmente, opte pela sua adoção ou não. Os ciclos devem ser opção da escola, e não apenas do sistema.

Em terceiro lugar, a implantação do regime de ciclos precisa de uma reforma curricular que contextualize os tempos e os espaços escolares e, sobretudo, a nova forma de avaliação. A avaliação institucional da escola e a avaliação do desempenho escolar do(a) aluno(a) são peças-chave do êxito ou do fracasso do projeto. A implantação dos ciclos não pode ser desvinculada de um estudo do processo avaliativo e das concepções de currículo e de conhecimento, e de uma ampla discussão com as escolas. Caso contrário, os ciclos podem acabar formando analfabetos diplomados. Se os ciclos forem entendidos como mera aprovação automática, corremos o risco de formar uma geração de analfabetos escolarizados (alguns afirmam que isso já está acontecendo!).

Sem essas pré-condições, a progressão continuada pode virar aprovação automática, perdendo sua característica democrática e inovadora. O regime de ciclos pode ajudar os alunos a gostar de aprender, através de uma avaliação dinâmica, formativa, contínua, estimulante e investigadora, como pode levá-los à acomodação de quem sabe que "vai passar" mesmo sem estudar. Eles podem aprender de forma mais rápida e prazerosa, como podem nada aprender. No regime de seriação, eles se sentiam culpados por não aprender num tempo rígido e inflexível; no regime de ciclos, eles podem culpar a escola. Na busca de culpados, quem perde é sempre o aluno e a sociedade. Há que se pensar mais em responsabilidades e em relações humanas emancipadoras.

A escola e o sistema de ensino têm obrigação não só de oferecer vagas para todos os que desejam aprender, mas têm também a obrigação de fornecer ao professor e ao aluno os meios para fazer aprender de forma prazerosa. O aluno não pode estudar só para a prova. Deve estudar porque está convencido de que o conhecimento é essencial para a sua vida, porque o conhecimento faz parte do seu projeto de vida, e não porque é uma obrigação.

Os argumentos usados hoje contra o regime de ciclos são numerosos: "falta referencial teórico"; "prejudica o interesse dos alunos"; "os alunos se tornam mais agressivos"; "o rendimento escolar cai dramaticamente"... Será que o problema está realmente na desseriação ou está nas condições do ensino-aprendizagem de nossas escolas? As condições de trabalho da maioria das escolas públicas são extremamente graves. Nesse cenário, o professor não consegue fazer outra coisa a não ser tentar cumprir, honestamente, o programa e manter a disciplina. Por isso, as famílias, antes de atribuírem ao regime de ciclos a falta de aprendizagem do aluno, as famílias, precisam ir às escolas para ver em que condições seus filhos "estudam". Em muitas delas é um milagre que ainda se aprenda alguma coisa. 
A coletânea inicia com a temática da reorganização do ensino fundamental na rede estadual de ensino do Estado de São Paulo. João Cardoso Palma Filho discute um conjunto de ações postas em prática pela Secretaria de Estado da Educação, através da Coordenadoria de Estudos e Normas Pedagógicas (Cenp), durante o governo Franco Montoro (1983 a 1986). Esse conjunto de ações contemplava dois grandes programas: o do Ciclo Básico e o da Reforma Curricular. O texto resgata o processo de reorganização do ensino fundamental iniciado naquele período, que teve início com a criação do Ciclo Básico (CB), mediante a publicação do decreto estadual no 21.833 , de 28/12/1983, e prosseguiu com a reformulação curricular que gerou as Propostas Curriculares para o Ensino de $1^{\circ} \mathrm{Grau}$, em que os objetivos educacionais e os conteúdos curriculares já eram apresentados em ciclos de estudos. Desse modo, os conteúdos do ensino fundamental ficavam reorganizados em três ciclos: Básico, Intermediário e Final. O Ciclo Básico reunia num continuum as duas séries iniciais do então ensino de primeiro grau; o Ciclo Intermediário reunia a $3^{\mathrm{a}}$, a $4^{\mathrm{a}}$ e a $5^{\mathrm{a}}$ séries, e o Ciclo Final agrupava a $6^{\mathrm{a}}$, a $7^{\mathrm{a}}$ e a $8^{\mathrm{a}}$ séries.

Nos textos seguintes, Marília Claret Geraes Duran apresenta uma análise das principais questões que dominaram cada período do complexo processo de implantação do Ciclo Básico nas escolas da rede estadual de São Paulo entre 1983 e 1994, vivido por pais, alunos, professores, diretores, supervisores, técnicos e especialistas em Educação e, mais amplamente, por toda a sociedade, numa abordagem histórica, organizando o período em quatro fases: 1983/1985 - a Proposta Política; 1985/1988 - a Proposta Pedagógica; 1988/1991 - a Jornada Unica no CB; 1991/1994 - a Reforma do Ensino.

$\mathrm{Na}$ perspectiva de explicitar a concepção de educação subjacente ao regime de ciclos, a autora enfatiza os aspectos mais ligados à proposta de alfabetização que a organização curricular em ciclos estabeleceu e que podem servir de indicadores de um modelo verdadeiramente novo de operar na escola.

No quarto artigo, Maria Leila Alves discute a política de formação continuada dos profissionais do ensino, desencadeada pela implantação do Ciclo Básico no período de 1983-1994, período em que se inauguram as primeiras políticas públicas de formação em serviço, coordenadas inicialmente pela Cenp/SE e, nos quatro anos finais, pela Fundação para o Desenvolvimento da Educação (FDE). Essas políticas instauraram-se com a preocupação de envolver os profissionais em atividades contínuas, organizadas em níveis centrais, regionais e sub-regionais, criando possibilidades concretas de enfrentamento da seletividade do sistema de ensino. Fazia-se necessário construir, com a rede de escolas, uma cultura pedagógica mais democrática e inclusiva, instaurando novos princípios e propostas para alfabetizar o conjunto de alunos e não apenas uns poucos privilegiados. Organizar a formação em serviço em processos e movimentos articulados nos três níveis hierárquicos do sistema de ensino, envolvendo o maior número possível de professores, delineava-se como uma possibilidade de superar os problemas de fragmentação e descontinuidade das ações desenvolvidas anteriormente, apontados pelas diversas avaliações realizadas. No esforço para superá-los, encontram-se os embriões da formação continuada. Muitas das propostas desenvolvidas na rede, no processo de implantação do Ciclo Básico, impulsionaram avanços na concepção de formação continuada, contribuindo para integrá-la aos discursos oficiais e aos dispositivos legais.

O último artigo, da mesma autora, à guisa de conclusão da Coletânea, retoma os fundamentos políticos, não apenas do projeto do Ciclo Básico, mas dos projetos sociais em geral, analisando-os a partir da cultura pedagógica brasileira, impregnada pelo ideário conservador, e também das intenções de mudança ou manutenção da ordem social em consonância com os grupos que propõem as políticas. O objetivo é enfatizar a importância da uma leitura crítica das demandas político-educacionais, pelos sindicatos de educadores, pelos professores e demais interessados na educação escolar, principalmente aquelas demandas que vão no sentido de manter ou ampliar a seletividade de ensino, como as relacionadas aos processos avaliativos.

O momento atual mostra-se propício para a retomada dessa discussão, uma vez que, nos meios acadêmicos, entre os profissionais de ensino, nas análises e reivindicações sindicais de entidades representativas do magistério, tem-se colocado a falsa 
dicotomia: promoção automática dos alunos x seriação do ensino.

Parabéns aos autores deste livro que tão lucidamente defendem o que se constitui conquista democrática. A criação do ciclo básico nos anos 80 foi um avanço. Ele deve ser preservado, criticado e melhorado.

Moacir Gadotti é professor titular da Faculdade de Educação da Universidade de São Paulo (USP) e diretor do Instituto Paulo Freire - São Paulo. 